\title{
Candy Crush Saga e estereotipias de gênero: a relação entre a interface visual e a aderência de diferentes públicos
}

\author{
Leonardo Filipe Batista Silva de Carvalho, UFRGS, lfilipebsc@gmail.com \\ Ygor Corrêa, PPGEducação UCS, correaygorprof@gmail.com \\ Fúlvia da Silva Spohr, UFCSPA, fulvia@ufcspa.edu.br
}

\begin{abstract}
Resumo. Este artigo investiga questões relativas às implicações da representatividade de gênero na interface visual do jogo Candy Crush Saga, a partir de um estudo de caso. Embora de aparência associada ao gênero feminino, o jogo sugere o rompimento de estereótipos, ao passo em que engaja jogadores de diferentes gêneros e subjuga a perspectiva de estereotipias fixas. Neste horizonte, uma pesquisa com 20 indivíduos foi realizada com o uso de questionário online, a fim de identificar preferências no que toca a interface visual e as mecânicas de jogo - a maneira como é jogado. O que destaca as relações entre a identidade visual do jogo, sua mecânica e o engajamento dos jogadores quanto aos possíveis estereótipos de gênero. Os resultados evidenciaram que o jogo promove a aderência de diferentes gêneros, corroborando que a categoria "gênero" é um construto social efêmero, constatação que pode orientar as práticas pedagógicas quanto da utilização de jogos em sala de aula.
\end{abstract}

Palavras-chave: interface visual, jogos casuais, engajamento, estereótipos de gênero

\section{Candy Crush Saga and gender stereotypes: the relationship between visual interface and the adherence of different audiences}

\begin{abstract}
This article investigates issues relating to the implications of gender representation in the visual interface of the game Candy Crush Saga from a case study. Although feminine in appearance, the game suggests the breaking of stereotypes, while engaging players of different genders and subduing the prospect of fixed stereotypes. Against this background, a survey of 20 individuals was carried out using an online questionnaire to identify preferences regarding the visual interface and the game mechanics - the way the game is played. This highlights the relationship between the visual identity of the game, its mechanics and the players' engagement regarding possible gender stereotypes. The results showed that the game promotes the adhesion of different genres, confirming that the category "gender" is an ephemeral social construct, a finding that can guide pedagogical practices regarding the use of games in the classroom.
\end{abstract}

Keywords: casual games, visual interface, engagement, gender stereotypes

\section{Introdução}

Os videogames são bastante populares, havendo pessoas que gastam mais tempo com eles do que com outros tipos de entretenimento. Isso torna significativo sua melhor compreensão, especialmente, no que toca ao estabelecimento de símbolos com possíveis impactos sociais (Williams et al., 2009). Neste aspecto, este estudo está situado no contexto de estudos culturais e de trabalhos como os de Behm-Morawitz e Mastro (2009), Cerdera e Lima (2016) e o mais recente de Spieler e Slany (2018), que correlacionam as estereotipias presentes em videogames e como elas afetam a percepção e até mesmo o envolvimento de seus jogadores. Dentro deste contexto, esta pesquisa parte da análise do jogo Candy Crush Saga (CCS) como forma de abordar questões relativas à concepção de gênero com base nos estudos de Butler (2010), para 
quem gênero é uma categoria socialmente instituída, que vai além da noção de determinismo biológico, a qual é comumente responsável pela normatização dos sexos masculino ou feminino.

Os estudos sobre gênero constituem um campo de estudos interdisciplinar destinado a analisar as relações sobre identidade de gênero, suas representações e estereotipias. Sob esta perspectiva, o estudo dos estereótipos de gênero presentes em CCS contribui para a proposição de estratégias pedagógicas críticas. Dado que inclui em seus fazeres, a problematização sobre a produção e representação de estereótipos de gênero em ambientes de jogos digitais. Traço que desnaturaliza o tema e que, segundo Cerdera e Lima (2016), contribui para a inclusão no espaço das escolas do debate sobre a desconstrução da identidade de gênero. Tomando sua representação nos videogames como instrumento de reflexão e aprendizagem.

Evidenciar a maior ou menor presença de estereotipias de gênero no contexto dos jogos permite ao professor problematizar este tema e selecionar de maneira adequada recursos didáticos que promovam a aderência de diferentes gêneros e, que acarretem objetivos de aprendizado previamente definidos. Deste modo, acredita-se que este estudo pode contribuir para a seleção de jogos digitais aplicados a contextos de ensino e aprendizagem, na medida em que podem apurar o olhar docente quanto à identificação de características que possam consolidar negativamente determinada estereotipia. Em especial, demonstrando como a reprodução do estereótipo feminino nestas mídias fomenta esta representação ao associar certas características e/ou atributos simbólicos ao comportamento esperado por homens ou mulheres.

No contexto contemporâneo, os jogos digitais destacam-se pela complexidade de fatores que mobilizam no âmbito social e político, atuando inclusive como campo de disputa por representatividade de gênero. A problematização sobre gênero advém do movimento feminista da década de 1970 (Butler, 2010a), o qual tem buscado elucidar as questões de gênero como derivadas de construções sócio-históricas, desvinculando o tema em termos de características biológicas. No caso dos jogos digitais, embora cada vez menos recorrente, ainda é possível observar a construção de identidades de gênero pautadas em características naturalizadas como masculinas e femininas, o que pode ser observado em design gráficos destinados a públicos específicos. No contexto deste estudo, objetivamos discutir questões da representatividade de gênero e, em especial, como essa fomenta a representação da identidade visual de um videogame.

A relevância de aspectos de caráter de gênero na interface visual de videogames é abordada por Cassell (1998) e Hartmann e Klimmt (2006), para os quais, boa parte dos jogos são de fato construídos com foco em um público de jogadores de gênero específico, mas que, de maneira geral, podem ganhar aderência por parte de outro gênero, quando membros deste outro grupo se identificam com o jogo. Com base nesta inferência, esta pesquisa caracteriza-se como um estudo de caso, sob a(s) representações de gênero presente(s) no jogo Candy Crush Saga, jogo de caráter casual (Soderman, 2011) que em linhas gerais, desperta a atenção de jogadores de diferentes gêneros, apesar de contar com uma caracterização visual que remete ao construto social feminino (tons de rosa, frutas, doces, etc.). O que teorizamos deve-se às estratégias que o jogo apresenta e que nos levou a submeter o Candy Crush Saga a uma pesquisa científica empírica como forma de desvelar o que possivelmente pode torná-lo capaz de romper com estereótipos e engajar jogadores do gênero masculino e feminino.

Frente a isso, apresentamos um estudo de caso (Fragoso; Recuero; Amaral, 2011) que submeteu 10 indivíduos do gênero masculino e 10 do gênero feminino à aplicação de um questionário online na rede social Facebook, para identificar de que maneira os jogadores entrevistados percebem a interface e a mecânica do jogo Candy 
Crush Saga. O estudo conduzido, analisa os fragmentos discursivos coletados sob a hipótese de que a aderência ao jogo pode romper barreiras de gênero, contribuindo para os estudos sobre o tema por evidenciar entre os jogadores respondentes, que a construção de gênero se trata de um construto social forjado na cultura sendo, portanto, performático (Butler, 2010b). As próximas seções exploram este tema da seguinte forma, 2 Games: a presença de estereotipias sexistas; 3. Jogos casuais: características e jogadores; 4. Candy Crush Saga: um game casual e sua mecânica de jogo; 5. O estudo de caso; 6. Análise de dados; e 7. Considerações Finais.

\section{Games: a presença de estereotipias sexistas}

Esta seção discute a presença de estereotipias sexistas em games com a intenção de compreender a influência da percepção de gênero na criação, divulgação e representação das personagens femininas em videogames. Estudos que analisam a representação das personagens femininas em videogames, como Bristot, Pozzebon e Frigo (2017), Romanus (2012) e Fortim (2008), constatam a existência de uma relação entre o aumento de mulheres como usuárias de videogames e a diminuição de estereotipias na representação e composição de personagens femininas (Cruz; Pimenta, 2015), visto que as players (jogadoras) têm aderido a games com elementos (cenário, personagem, etc.) que conservam a identidade do gênero masculino. Todavia, os videogames ainda são largamente desenvolvidos para um público específico, quer seja do gênero masculino ou feminino e, portanto, são pensados de forma a atender as preferências e inclinações de seu público alvo (Prensky, 2010; Sweeny, 2010).

Bussey e Bandura (1999) definem o conceito de gênero na perspectiva das Ciências Humanas, a partir da Teoria Social, como papéis resultantes de ampla influência social que operam de forma interdependente em diferentes subsistemas sociais. Sobre o conceito há influência também das estruturas corporais e biológicas, que permitem pluralidade e não estão confinadas a um tipo fixo de diferenciação entre gêneros. Viés em que a teoria feminista de Butler (2010a) se apoia para cunhar o conceito de gênero como um ato intencional e performativo, que produz significados e que constitui uma categoria forjada na cultura que "não deve ser meramente concebido como a inscrição cultural de significado num sexo previamente dado" (Butler, 2010b, p. 25) e que "[...] tem de designar também o aparato mesmo de produção mediante o qual os próprios sexos são estabelecidos".

A teoria de Butler (2010a) também corrobora a manutenção de estereotipias a partir da criação de artefatos (Igima, 2013), visto que a noção de gênero é construída e definida pela cultura e imposta sobre os corpos, tanto quanto o construto social subjetivo de gênero masculino ou feminino, resultante da interação social na vida cotidiana, tal como a distinção de sexos (Kessler; McKenna, 1985). Distinção que é categorizada, a partir de uma conduta social normativa e instituída, que classifica as características biológicas de homens ou mulheres (West; Fenstermaker, 1995), enquanto o gênero está relacionado ao comportamento dos sujeitos em relação ao que se espera da performance masculina ou feminina (Butler, 2010b).

O estereótipo é, portanto, a percepção geral de um grupo sobre os atributos pessoais de membros de outra comunidade de sujeitos (Ashmore; Boca, 1981). O que constrói e propaga uma identidade social que atribui papéis estáticos e não performáticos para diferentes mídias, na forma de personagens com características masculinas que são protagonistas em relação às personagens femininas. Aspecto que distorce tanto no universo real como nas diferentes formas de ficção, os interesses e papéis contemporâneos possíveis ao gênero feminino. O que Sweeny (2010) destaca na 
comum imagem submissa apresentada pelas mulheres, enquanto gênero feminino, nos videogames em relação a personagens do gênero oposto, e que para Dietz (1998) gera quatro estereotipias que classificam o gênero feminino nessas mídias: a) objetos sexuais ou prêmios; b) vítimas de violências; c) papéis femininos padrões; e d) heroínas e intérpretes de personagens de ação.

A estereotipia característica de um jogo é um aspecto que faz com que jogadores optem por se envolver ou não com ele. Contudo, ela não é o único aspecto que motiva os jogadores a interagir e explorar o jogo. A motivação de um indivíduo em relação a um jogo é o motor principal que o impulsiona a interagir com esse ambiente, quer seja intrínseca, capacitando a autonomia e à autodeterminação dos sujeitos, ou extrínseca, articulada ao desempenho, com objetivo em uma recompensa (Guimarães, 2011). Em resumo, na motivação intrínseca o jogador é motivado a desafiar-se, unicamente para superar o próprio desafio, enquanto na motivação extrínseca o foco do jogador está principalmente na recompensa daquela ação.

Segundo Guimarães (2011), a motivação é essencial para que o indivíduo sinta desejo de jogar, de forma a envolvê-lo e a reter sua atenção nos objetivos do jogo. Propósitos que para Jenkins (1998), também podem ser categorizados em diferentes públicos, onde títulos voltados à construção de famílias (The Sims), resolução de quebra-cabeças (Tetris), ou um simuladores de carreiras (Vet Emergency), são vistos como mais interessantes para um público feminino, enquanto títulos com ênfase no combate e/ou na competição, como World of Warcraft, Mortal Kombat e Grand Theft Auto, são de modo geral voltados ao público masculino (Prensky, 2010). Em qualquer dos casos, a escolha por um tipo de jogo não é determinada apenas pelas estereotipias das personagens presentes, sendo influenciada também por outras componentes, como o cenário, narrativa e mecânicas de solução dos problemas. Portanto, a motivação está para além do gênero, pois, se o gênero é construído por meio de uma performance quanto aos interesses e às ações do jogador, ele, por sua vez, escolhe envolver-se em um contexto em razão do quanto os elementos presentes ativam sua motivação. Jogadores de diferentes gêneros se interessam por jogos distintos, motivados por aspectos únicos da totalidade do jogo e não apenas por uma de suas características. Para corroborar essa visão, iniciamos com uma exposição de como Candy Crush Saga se classifica dentro do universo dos videogames, tal como destacado a seguir.

\section{Jogos casuais: características e jogadores}

Candy Crush Saga foi escolhido para este estudo de caso por ser popular entre diferentes gêneros a época do estudo. O jogo se enquadra no conceito de jogo casual, que para Soderman (2011) se distingue de outras modalidades de jogo por ser, em geral, jogado por mulheres como passatempo por curtos períodos (Keschinger, 2013; Coelho, 2014). Seu oposto seriam os jogos hardcore, jogos de viés extremamente competitivo e associados com os interesses de jogadores do gênero masculino, como os jogos de tiro em primeira pessoa como Halo, Call of Duty, ou o já antigo Counter Strike (Keschinger, 2013; Coelho, 2014). Aderir a determinado tipo de jogo rotula o jogador como parte do grupo vinculado àquele gênero e reforça os estereótipos que empresas de jogos utilizam como estratégia de marketing para atingir a uma dessas duas subculturas (Keschinger, 2013).

De fato, jogos casuais já estavam disponíveis há muito tempo para Personal Conputers (PCs), mas eram vistos como jogos focados em uma demografia feminina (de maior faixa etária), interessada, principalmente, em passar o tempo, como afirma Reparaz (2007), que oferece também em um artigo para o site gamesradar, 
especializado em jogos, uma definição para esses jogos, que observa a maneira como eles são jogados e os descreve como jogos simples, fáceis de começar a jogar e de desenvolvimento relativamente barato. Afirmações que a Associação Internacional de Desenvolvedores de Jogos corrobora, ao classificar os jogos casuais como tendo controles menos complexos, com mecânicas de jogo mais simples e menor necessidade de investimento de tempo para avançar pelo jogo (Wallace; Robbins, 2006), podendo serem aproveitados em curtos espaços de tempo, como pequenas pausas ou filas de espera. O que, novamente, coloca como seus opostos os jogos hardcore, que exigem grande investimento de tempo e recursos para se avançar pelo jogo e obter as conquistas disponíveis (Keschinger, 2013).

Hoje, jogos casuais tendem a ser desenvolvidos para um público alvo variado e se tornaram extremamente acessíveis e populares em razão da difusão dos dispositivos móveis, bem como por seu fácil aprendizado, maior tolerância a falhas, níveis curtos e de alta rejogabilidade, baixo tempo de carregamento e temas não violentos (Meretzky, 2007). Traços que não são barreiras para jogadores mais competitivos que desejem vivenciar esses títulos de uma perspectiva hardcore, repetindo as fases até obter as maiores pontuações e, como sugere Keschinger (2013), investindo tempo para explorar e interagir com o ambiente de jogo e para observar e competir com os demais jogadores.

\section{Candy Crush Saga: um game casual e sua mecânica de jogo}

Candy Crush Saga é um jogo casual integrado às redes sociais, tipo de jogo em que o jogador usa sua conta em uma rede social para interagir com seus contatos a partir do jogo, desafiando-lhes ou solicitando-lhes ajuda (Coelho, 2014). O que em CCS, surge na comparação entre a pontuação do jogador e a de seus contatos que possuem o jogo, assim como em pedidos de ajudas (vidas, movimentos extras, etc.), ou convites para fazer parte do jogo (Figura 1 (a)). Desenvolvido pela King (Midasplayer.com Limited) e lançado no final de 2012, Candy Crush Saga conta a narrativa da garotinha Tiffi, que parte em uma aventura onde se depara com diferentes situações que soluciona em resposta a seu avanço pelas fases do jogo (Figura 1 (b)).

O jogo mescla elementos de fantasia e puzzle, "quebra-cabeça", com o tema visual de uma fábrica de doces e uma mecânica que alude a jogos de "Match-3", que consistem na resolução de desafios através da combinação de ao menos três peças iguais (no caso, doces) dentre várias (Arruda; Petterman, 2013). Combinar ao menos três doces iguais os destrói e reacomoda os demais, o que, a depender do planejamento do jogador, pode desencadear combinações ou sequências de combinações automáticas (combos). Cada combinação maior que três gera um doce especial (Figura 1 (c)) que pode ser usado para diferentes fins. Este tipo de doce também pode ser adquirido na loja do jogo (Candy Crush Saga Wiki, 2014; Arruda; Petterman, 2013).

Após um ano de seu lançamento o Candy Crush Saga contabilizou mais de 93 milhões de usuários diários ativos (Fiegerman, 2014; Arruda; Petterman, 2013). No mesmo ano, ele foi considerado um jogo casual viral nas redes sociais (Coelho, 2014), capaz de angariar e manter jogadores dos gêneros masculino e feminino, apesar de uma caracterização visual com um estereótipo feminino ou mesmo infantil (Arruda; Petterman, 2013), como ilustram as capturas de tela da Figura 1. Sete anos após seu lançamento, em maio de 2019, o CCS conta ainda com 10 milhões de usuários diários ativos apenas na rede social Facebook (Statista, 2019). Para a maioria desses jogadores, o desafio proporcionado em alcançar pontuações cada vez maiores, utilizando da mecânica de planejar e gerar combinações que resultam em sequências de combos, é o 
verdadeiro elemento atrativo do jogo, como será demonstrado na seção 6. Antes disso, apresentaremos a metodologia adotada no estudo de caso.

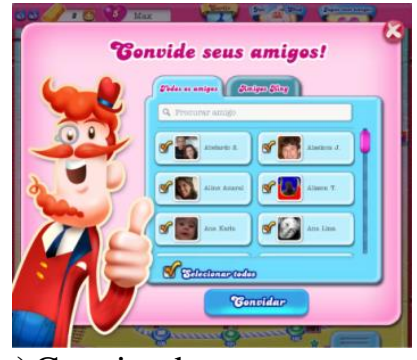

(a) Convite de contatos para a comunidade de jogadores

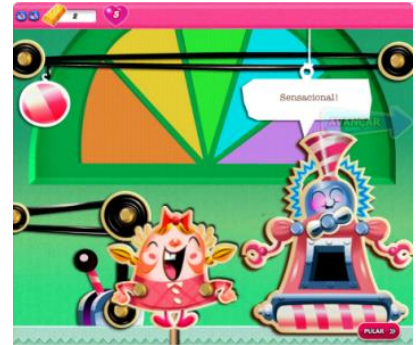

(b) Tiff ajudando um personagem

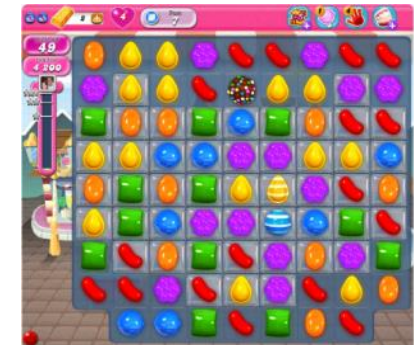

(c) Fase do jogo e diferentes variedades de doces

Figura 1 - Telas de Jogo do Candy Crush Saga.

Fonte: captura de tela realizada pelos autores. Copyright: King Digital Entertainment

\section{Estudo de caso}

Este estudo de caso configura-se em uma pesquisa quanti-qualitativa com base em métodos de pesquisa na Internet (Fragoso; Recuero; Amaral, 2011), por meio da rede social Facebook, com 20 sujeitos, 10 homens e 10 mulheres, e usuários de smartphones com configurações compatíveis a do jogo Candy Crush Saga. A faixa etária feminina foi entre 17 a 48 anos e a masculina entre 26 e 37 anos. Todos os participantes foram submetidos à aplicação de um questionário online com 15 perguntas, uma (01) dissertativa e 14 objetivas, que elencaram aspectos como: idade; sexo; frequência de jogo; local; estrutura geral; aparência visual; interação; gênero de jogadores; desafio; pontuação; competição; fases; tempo; feedback; e interação via rede social. O cunho etnográfico online do estudo comporta uma abordagem via rede social a partir de Fragoso, Recuero e Amaral (2011), com a Internet como meio de acesso a informações para a construção de conhecimento acerca do assunto para fins de pesquisa. Tal como o questionário online que, enquanto método, estratifica dados referentes aos sujeitos entrevistados. O conteúdo da questão dissertativa foi analisado sob a ótica de Bardin (2011) da Análise de Conteúdo (AC), que permite identificar unidades de sentido nos discursos, além do uso de um mesmo fragmento discursivo, para corroborar mais de um tema (unidade).

\section{Análise de dados}

A coleta de dados a partir do questionário contou com 20 participantes, 10 homens e 10 mulheres, todos com experiência com o jogo na versão para dispositivos móveis. Em relação às proposições do trabalho, a questão 01 verificou a frequência de jogo no Candy Crush Saga, com 07 das 10 mulheres consultadas afirmando jogar 05 ou mais vezes por semana, e apenas 02 dos 10 homens apresentando frequência similar. Os demais participantes do sexo masculino afirmaram jogar CCS 04 vezes ou menos por semana, com apenas 02 das 10 mulheres com frequência similar. A relação entre essas variáveis é apresentada na Figura 2. A questão 02 investigou os locais comuns de jogo dos sujeitos e identificou que, apesar da natureza casual e disponibilidade para dispositivos móveis, 17 dos 20 sujeitos afirmaram jogá-lo em casa, com apenas 01 homens e 02 mulheres afirmado jogá-lo em outros contextos.

A questão 03 verificou os maiores atrativos do jogo para os sujeitos, havendo unanimidade entre homens e mulheres pelo desafio proporcionado pela mecânica de "Match-3" do jogo e, como indica a Figura 3, apenas 01 mulher dentre todos os 20 
respondentes tem preferência por outro elemento que não o desafio do jogo. Em contraste, a questão 04 que aborda a percepção dos sujeitos acerca do tema visual do jogo verificou que 06 dos homens e 06 das mulheres consultados julgam a aparência visual do jogo atraente. Os demais 08 respondentes se mostraram bastante divergentes em relação a esse ponto, como mostra o gráfico da Figura 4. O que se pode inferir é que, a aparência visual do jogo revela-se como um fator de engajamento de diferentes gêneros, mesmo havendo pouca diferença de engajamento do público feminino em relação ao público masculino. O que é apoiado pela questão 05, que avalia a clareza da aparência visual do jogo, que foi considerada clara ou muito clara por $90 \%$ do total de entrevistados (apenas 02 participantes do gênero masculino afirmaram que este aspecto é pouco claro). Novamente, isto aponta que a maioria dos jogadores de Candy Crush são atraídos por seus desafios, identificados pela questão 06 como desafiadores, ou muito desafiadores, por 06 dos 10 homens e 07 das 10 mulheres.

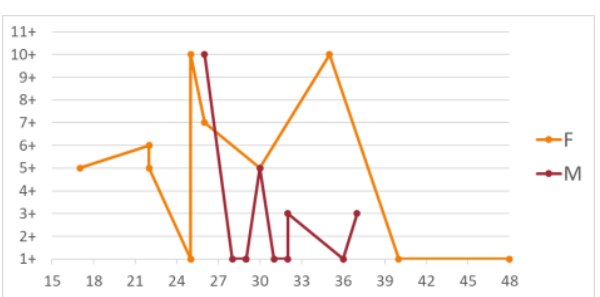

Figura 2 - Relação entre gênero, idade (eixo X) e frequência de jogo semanal (eixo Y) dos jogadores. Fonte: autores

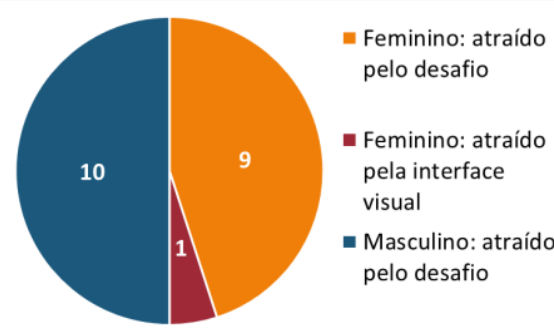

Figura 3 - Relação de jogadores atraídos pelo desafio do jogo e pela interface visual. Fonte: autores

Esses dados reforçam a posição dos jogadores sobre o jogo ser voltado a um público feminino, masculino ou neutro. A análise do gráfico obtido pela questão 07 (Figura 5) aponta que a maior parte dos sujeitos associa o jogo a um público neutro. $\mathrm{O}$ que é complementado pela questão 08, que investiga a opinião dos sujeitos em relação ao porquê de o jogo se relacionar a um gênero ou outro. Os fragmentos discursivos extraídos das narrativas de 04 sujeitos do gênero masculino e 04 do gênero feminino (Quadro 1), a partir da metodologia de AC de Bardin (2011), indicam que os sujeitos de fato consideram o jogo voltado a um público neutro.

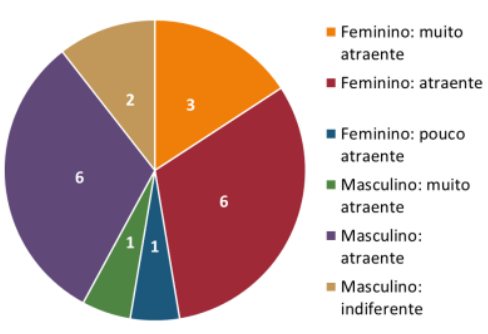

Figura 4 - Relação entre gênero e atratividade da aparência visual do jogo. Fonte: autores

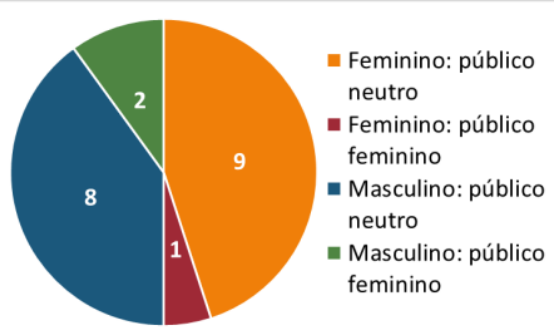

Figura 5 - Visão dos jogadores sobre CCS ser voltado a um público específico. Fonte: autores

A questão 09 foca a relevância da sensação de recompensa para os sujeitos ao receber uma pontuação alta, um upgrade (aprimoramento), ou concluir uma fase. Dezessete dos 20 sujeitos questionados sentem-se recompensados por seus esforços, com apenas 02 mulheres e 01 homem se dizendo indiferentes a isto. Na questão 10, que questiona o que sentem ao superarem a pontuação de seus amigos, treze dos 20 sujeitos afirmaram se sentir recompensados por essa conquista, enquanto 05 homens e 02 mulheres afirmaram não jogar competindo com seus amigos. A questão 11 abordou os sujeitos sobre a facilidade de jogar casualmente em qualquer ambiente, dezessete respondentes concordaram com a afirmação, com 01 mulher afirmando que a facilidade 
de acesso não é um aspecto que considera importante ao jogo e 01 homem e 01 mulher afirmando indiferença ao aspecto. A questão 12, relacionada à contagem de tempo pelo cronômetro de jogo é vista por 09 mulheres e 06 homens como geradora de tensão na realização de jogadas; 01 mulher e 01 homem afirmaram que a mecânica não lhes exprime tensão; para 01 mulher e 03 homens esse fator é indiferente.

Quadro 1 - Relatos sobre a percepção de um público específico para o Candy Crush. Fonte: autores

\section{Feminino}

"Observei que o jogo atrai a todos os públicos, em relação à faixa etária de idade e gênero"

"Acredito que seja um jogo destinado a qualquer um, não necessariamente precisamos limitar os jogos ao público masculino ou feminino apenas"

"As pessoas que conheço e que jogam são bem divididas entre homens e mulheres"

"Apesar de ser bem colorido, acho que o público masculino fica mais interessado com os objetivos do jogo do que a aparência do mesmo"

\section{Masculino}

"Este é um jogo que cabe para qualquer gênero sexual e idade"

"Os desafios que o jogo apresenta são para qualquer sexo embora a temática, acredito eu, sejam mais atrativas ao público feminino"

"É um jogo de desafio e não caracterizado por gênero"

"Não há relação do jogo em si com sexo, masculino e feminino, nem é apresentado nenhuma característica que defina a qual público ele é destinado"

Ao questionar os sujeitos sobre o controle que sentem sobre o que acontece no jogo, na questão 13, dez mulheres e 07 homens responderam não se sentir no controle, enquanto 03 homens afirmaram se sentir no controle. Em relação aos tipos de feedback (auditivo ou visual) que o jogo propicia, investigado pela questão 14, dois (02) homens e 01 mulher consideram-se estimulados pela música e pelos estímulos audiovisuais do jogo. Em contrapartida, 01 homem afirmou sentir-se estimulado apenas pelo fundo musical e 03 homens e 05 mulheres afirmaram sentirem-se estimulados apenas pelos feedbacks textuais ou orais. Ainda, 04 homens e 04 mulheres responderam não se sentirem estimulados por nenhum deles. A questão 15 verificou o hábito dos sujeitos de convidar amigos da rede social Facebook para interagir com o jogo de alguma forma. Apesar do vínculo com a referida rede social, em geral, os sujeitos afirmaram não convidar contatos para jogar, embora 09 das 10 mulheres tenham afirmado interagir com seus contatos para solicitar vidas e ajuda para o desbloqueio de fases. Apenas 01 mulher informou enviar convite a seus amigos para que esses façam parte do jogo.

\section{Considerações finais}

A análise realizada evidenciou que o jogo Candy Crush Saga é jogado tanto por sujeitos que se autodeclararam pertencendo as identidades de gênero masculino e feminino. Contudo, infere-se a partir dos dados apresentados que as mulheres possuem maior frequência de interação com o jogo, assim como tomam maior proveito da integração deste com o Facebook para expandir a experiência do jogo à sua rede de contatos. $\mathrm{O}$ que é menos expressivo entre os homens.

Ainda que essas características reforcem o pressuposto do estereótipo da caracterização visual do jogo, a pesquisa evidenciou que apenas $15 \%$ dos entrevistados consideram o jogo como destinado a um público feminino, enquanto $85 \%$ dos entrevistados o consideram voltado a um público neutro. Percentuais que se relacionam a $95 \%$ do total de entrevistados considerarem o desafio proporcionado pelo jogo seu maior atrativo e que corroboram que apenas $10 \%$ dos entrevistados considerem os desafios do jogo pouco atraentes. Para esses $95 \%$ os desafios proporcionados pelo jogo atuam fortemente como motivadores intrínsecos (Guimarães, 2011), com o maior atrativo do jogo sendo as atividades propostas. Os entrevistados afirmaram ainda não necessitar de motivadores extrínsecos (Guimarães, 2011), já que os estímulos audiovisuais, feedbacks, e a interação com as atividades do jogo lhes são recompensas suficientes. 
Os dados coletados apontam que Candy Crush Saga possui potencial para dissolver os limites sociais impostos àquilo esperado dos gêneros masculino e feminino (Butler, 2010a; Fortim; Monteiro, 2013). O que, por sua vez, auxilia na desconstrução do próprio conceito de gênero, que de acordo com Butler (2010b) é um construto social sempre relativo à um conjunto específico de relações, cultural e historicamente convergentes. Visto que, além de muitos homens apreciarem o jogo, o mesmo presta contribuição para o aumento do número de mulheres jogadoras, como aponta Fortim e Monteiro (2013). Um dado relevante indicado por este estudo foi que, apesar de sua portabilidade, o jogo tem sido utilizado predominantemente no ambiente residencial, o que abre precedente para estudos futuros quanto às preferências dos sujeitos em como interagir com jogos casuais.

Os dados revelam que sujeitos do gênero feminino realmente se interessam pelo jogo e que os jogadores do gênero masculino não se mostram desconfortáveis frente à interface do jogo ou a sua mecânica. Como um todo, a aderência ao jogo pode ser vista nos fragmentos discursivos da seção 6, extraídos das narrativas analisadas. Outra observação é que a definição de gênero precisa ser compreendida como um construto social e performático, o que reforça a noção de que sujeitos do gênero masculino podem aderir a jogos que, a priori, tenham sido desenvolvidos para o público feminino.

No que tange ao objetivo de sensibilizar os docentes para o debate sobre a produção de estereótipos de gênero expressivamente marcados ou não no contexto de jogos digitais, entende-se que este estudo apontou para aspectos que podem maximizar ou minimizar a produção ou o destaque de estereotipias nessas mídias. Como no caso da mecânica de jogo, que, pelos resultados analisados, mostra-se como um fator de maior apelo do que a existência ou não de estereotipias em sua representação visual. O que, consequentemente, promove a aderência de jogadores de diferentes gêneros e, junto ao planejamento de ações de ensino e clareza na definição dos objetivos de aprendizagem, contribui para discussões que elucidem e dissolvam barreiras de gênero.

\section{Referências Bibliográficas}

ARRUDA, C. F.; PETERMANN, J. A. Construção da Narrativa e a Interação Com o Usuário: A Geração de Sentido Aplicada ao Candy Crush Saga. In: V SIPECOM Seminário Internacional de Pesquisa em Comunicação. 2013.

ASHMORE, R. D.; DEL BOCA, F. K. Cognitive processes in stereotyping and intergroup behavior, v. 1, p. 35, 1981.

BARDIN, L. Análise de Conteúdo. 6. ed. São Paulo: Almedina. 2011.

BEHM-MORAWITZ, Elizabeth; MASTRO, Dana. The effects of the sexualization of female video game characters on gender stereotyping and female self-concept. Sex roles, v. 61, n. 11-12, p. 808-823, 2009.

BRISTOT, P. C.; POZZEBON, E.; FRIGO, L. B. A representatividade das mulheres nos games. XVI SBGames. Curitiba, 2017.

BUSSEY, K; BANDURA, A. Social cognitive theory of gender development and differentiation. Psychological Review, v. 106, n. 4, p. 676, 1999.

BUTLER, J. Corpos que pesam: sobre os limites discursivos do "sexo". O corpo educado: pedagogias da sexualidade. Belo Horizonte: Autêntica, 2010a.

Problemas de gênero: feminismo e subversão da identidade. Trad. Renato Aguiar. Rio de Janeiro: Civilização Brasileira. 2003. História do corpo, v. 1, p. 19130, 2010.b

CANDY CRUSH SAGA Wiki. Candies. Disponível em: 〈https://bit.ly/2HGIyfG〉. Acesso em 19 de julho de 2014. 
CASSELL, J. Chess for girls?: Feminism and computer games. 1998.

CERDERA, C. P.; LIMA, M. R. O. Estereótipos de gênero em videogames: diálogos sobre sexismo, homofobia e outras formas de opressão na escola. XV Simpósio Brasileiro de Jogos e Entretenimento Digital, p. 955-961, 2016.

COELHO, P. M. F. "Candy Crush Saga" o Game Fenômeno das Redes Sociais/" Candy Crush Saga" Game fenómeno de las redes sociales. Revista Hipertexto (descontinuada), v. 4, n. 1, p. 22-40, 2014.

CRUZ, C. A. G.; PIMENTA, F. J. P. Jogos eletrônicos, protagonistas femininas e redução de estereótipos: a série Tomb Raider. Anagrama, v. 9, n. 1, p. 1-16, 2015.

DIETZ, T. L. An examination of violence and gender role portrayals in video games: Implications for gender socialization and aggressive behavior. Sex roles, v. 38, n. 56, p. 425-442, 1998.

FRAGOSO, S.; RECUERO, R.; AMARAL, A. Métodos de pesquisa para internet. Porto Alegre: Sulina, v. 1, 2011.

FIEGERMAN, S. 'Candy Crush' Is Bigger Than Twitter, But Probably Not For Long. Mashable: The Social Media Guide, 2005-2014. 2014. Disponível em: $<$ https://bit.ly/1kSuq37>. Acesso em 19 de julho de 2014.

GUIMARÃES, S. E. R. Motivação intrínseca, extrínseca e o uso de recompensas em sala de aula. A motivação do aluno: contribuições da psicologia contemporânea. 3.ed. Petrópolis: Vozes, p.37-57, 2004.

FORTIM, I. Mulheres e Games: uma revisão do tema. Simpósio Brasileiro de Jogos e Entretenimento Digital-SBGames, v. 7, p. 31-38, 2008.

FORTIM, I.; MONTEIRO, L. Choose your character: mulheres e personagens femininos nos videogames. XII Simpósio Brasileiro de Jogos e Entretenimento Digital, São Paulo, São Paulo, 2013.

HARTMANN, T.; KLIMMT, C. Gender and computer games: Exploring females' dislikes. Journal of Computer-Mediated Communication, v. 11, n. 4, p. 910-931, 2006.

IGIMA, G. Lara Croft: A representação feminina na trama, comunicação e venda de jogos de videogame. Rompimento ou fixação da ideologia machista. XII Simpósio Brasileiro de Jogos e Entretenimento Digital, São Paulo, São Paulo, 2013.

JENKINS, H. Voices from the combat zone: Game grrlz talk back. In: From Barbie to Mortal Kombat. MIT Press, 1998. p. 328-341.

KESCHINGER, B. T. Devising a formula for defining casual and hardcore through experience. Gamasutra, 2013. Disponível em: <https://ubm.io/2JYvdSO>. Acesso em 19 de julho de 2014.

KESSLER, S. J.; MCKENNA, W. Gender: An ethnomethodological approach. University of Chicago Press, 1985.

MERETZKY, S. E. Casual Games Summit. Game Developers Conference, 2007. Lecture.

REPARAZ, M. The death of hardcore gaming?. Games Radar. 2007. Disponível em: < https://bit.ly/2waKgRp>. Acesso em 19 de julho de 2014.

ROMANUS, Juliana Saldanha. Gênero em jogo: um olhar sobre personagens e as representações de tipos de feminilidades e masculinidades nos games de ação contemporâneos. 2012. Trabalho de Conclusão de Curso. Universidade Tecnológica Federal do Paraná.

PRENSKY, M. Não me atrapalhe, mãe - Eu estou aprendendo! São Paulo: Phorte. 2010.

SODERMAN, B. A. Interpreting Video Games through the Lens of Modernity. Diss. Providence: Brown University. 2011. 
SPIELER, B,; SLANY, W. Game Development-Based Learning Experience: Gender Differences in Game Design. arXiv preprint arXiv:1805.04457, 2018.

STATISTA. Most popular Facebook games as of May 2019, based on number of daily active users (in millions), 2019. Disponível em: <https://bit.ly/2hXTkQn>. Acesso em: 18 maio 2019.

SWEENY, R. W. Pixellated Play: Practical and theoretical issues regarding videogames in art education. Studies in Art Education, v. 51, n. 3, p. 262-274, 2010.

WALLACE, M.; ROBBINS, B. Casual games white paper. IGDA Casual Games SIG, 2006. Disponível em: <https://bit.ly/2ECH1a7>. Acesso em 19 de julho de 2014.

WEST, C.; FENSTERMAKER, S. Haciendo la diferencia. Género y Sociedad. V. 9, n. 1, p. 8-37. 1995.

WILLIAMS, D. et al. The virtual census: Representations of gender, race and age in video games. New Media \& Society, v. 11, n. 5, p. 815-834, 2009. 